\title{
TOMÁS RODRÍGUEZ RUBÍ Y EL DRAMA HISTÓRICO DE INTENCIÓN POLÍTICA: ESTUDIO Y CONSIDERACIONES SOBRE UN SUBGÉNERO DRAMÁTICO DE CLARO ALCANCE SOCIAL
}

\author{
Víctor Cantero García ${ }^{1}$ \\ I. E. S. "Padre Luis Coloma" (Jerez de la Frontera, Cádiz)
}

\begin{abstract}
RESUMEN: El articulista centra su colaboración en el estudio de la personalidad dramática y política de Tomás Rodríguez Rubí. Su importante contribución al desarrollo de las reformas teatrales del XIX y su decidida apuesta por los dramas históricos de intención política constituyen el objeto de la presente exposición. Dentro de nuestras posibilidades tratamos de rescatar del olvido a un escritor que compaginó como pocos su vida política con su profesión dramática. Fruto de ello son un conjunto de obras en las que la crítica a los abusos del poder, los cuales son una muestra más del empeño de Rubí por eliminar las prácticas corruptas en la gestión de los asuntos públicos.
\end{abstract}

ABSTRACT: The subject of this article deals with the dramatic personality and the politic affairs of Tomás Rodríguez Rubí. His decisive contribution to the development of the dramatic reforms in the 19th century and his historic plays with political purpose are the aim of our research. Our intention is to recover Rubí from oblivion and to show what a famous dramatist he was. We have studied some of his most important plays, in which he wrote hard criticisms against the corruption in the upper class.

PALABRAS CLAVE: Literatura española; siglo 19; Tomás Rodrïguez Rubí; Drama histórico; Política.

KEYWORDS: Spanish literature; Nineteenth Century; Tomás Rodrïguez Rubí; Historical drama; politics.

Escasa es la atención que la crítica literaria ha prestado al estudio del drama histórico decimonónico de intención política, un subgénero teatral digno de toda consideración por parte de la investigación literaria. Tal carencia llamó en su momento mi atención y a subsanarla me apresto con la presente colaboración. Muchos son los asuntos, temas y acontecimientos dramáticos del XIX que aún esperan ser rescatados del olvido por aquellos estudiosos que tienen puesto su interés en el teatro de dicho siglo, y el que aquí se considera es tan sólo uno

1. Doctor en Filología Hispánica por la Universidad de Cádiz. Investigador, miembro del Grupo Oficial de Investigación, Clave: HUM-593. UCA 
de ellos. Nuestro artículo pretende acercar al lector a uno de los fenómenos que, cuando menos, resulta curioso y sorprendente; nos referimos a la figura del dramaturgo-político o del político-dramaturgo, según sea el peso específico de cada una de las facetas del citado binomio, la cual estuvo presente en la literatura dramática del siglo ya mencionado.

Puestos a elegir uno de los más distinguidos representantes de tan peculiar combinación de intereses profesionales, me pareció que Tomás Rodríguez Rubí (Málaga, 1817- Madrid, 1890) podría ser el más adecuado. Una elección que se fundamenta no sólo en su dilatada experiencia en ambos campos, sino en su reconocido influjo y su sólida contribución a las mejoras y reformas del maltrecho teatro español de la segunda mitad del XIX. El acierto de nuestra selección es ratificado por su amigo Antonio María Fabié, quien sucedió a Rubí como académico y a él dedicó su discurso de ingreso. En las últimas frases de citado discurso encontramos la clave de nuestro tino, pues a juicio del citado estudioso:

" El concierto unánime de elogio que tributaron a su memoria los periódicos, órganos en aquella, más que en otras ocasiones, de la opinión y de los sentimientos del público, fue tributo debido a los méritos del poeta y a las virtudes del ciudadano, pues del Sr. Rubí puede decirse que, así en las esferas del Arte, como en las de la Administración y la Política, deja en su vida un ejemplo que imitar a las generaciones presentes y futuras, por lo que la Patria le contará siempre entre sus hijos insignes y predilectos"2

Con nuestra aproximación a la compleja y singular personalidad de Rubí pretendemos rescatar del olvido a uno de los autores dramáticos que con más acierto supo convertir el teatro en óptimo instrumento para la crítica social y política. Nuestro autor, al ocupar altos cargos y responsabilidades en los diversos Gobiernos de Isabel II, cuenta con todos los elementos necesarios para escribir dramas y comedias que, bajo el pretexto de ser históricos, son auténticos alegatos políticos contra las corruptelas, nepotismos, conjuras, intrigas y luchas de intereses que minan el poder de una monarquía isabelina cada vez más debilitada y abocada al inevitable fracaso. Con el estudio de un número limitado de obras de intención política elaboradas por Rubí, conseguiremos que el lector conozca las especiales cualidades de un autor que logró sintonizar como pocos con los intereses de los espectadores. Unas piezas que son el mejor testimonio sociológico de los vaivenes políticos y sociales que sacudieron a España en las décadas de la monarquía isabelina.

2. Fabié, Antonio María. "Tomás Rodríguez Rubí", en Discursos leídos ante la Real Academia Española. Madrid. Tipografía de Huérfanos, 1891, p. 26 
Esta fructífera combinación de dramaturgia y política propició que de la pluma del autor malagueño naciesen un conjunto de obras, entre las que cabe destacar: $L a$ rueda de la fortuna (1843) y segunda parte (1847), La Corte de Carlos II (1846), Alberoni (1846), Isabel la Católica (1850) y Bandera negra (1847). Ellas representan el mejor legado dramático de una figura literaria y política cuya compleja personalidad es imposible de reflejar en el limitado espacio de esta exposición. Al estudio de algunos de dichos textos, al eco social que produjeron y a la habilidad de Rubí para hacer política desde el teatro vamos a dedicarnos en las siguientes páginas. Con las ejemplificaciones aquí analizadas, nos resultará más sencillo comprender la capacidad del espectáculo teatral decimonónico para conquistar voluntades políticas y para poner en solfa los vicios y errores de un estamento social que convirtió el ejercicio político en un camino para el lucro personal.

\section{El itinerario biográfico de un dramaturgo polifacético y de un político comprometido}

No es nuestro propósito presentar al lector todos los pormenores de la vida y la obra de Rubí, sino ofrecerle tan sólo los rasgos esenciales que le ayuden a comprender cómo su vocación literaria se combinó adecuadamente con su dedicación a la política. El acierto en el desempeño de ambas tareas proporcionó a nuestro dramaturgo un puesto destacado en la escena española, en la cual irrumpe justo cuando el drama histórico había alcanzado las más altas cotas de hipertrofia de la mano de autores como Cefirino Suárez Bravo, Luis de Eguilaz, Narciso Serra o Manuel Fernández y González³. La fecundidad de Rubí rivalizó con la de Bretón, pues escribió casi 100 dramas, 59 tan sólo en el periodo 1840-1857. Hartzenbusch lo calificó en 1850 como el dramaturgo más aplaudido de todos los de su época por obras como Del mal el menos (1840), Isabel la Católica (1843), La bruja de Lanjarón (1843), La rueda de la fortuna (1843), Bandera negra (1844) y La Corte de Carlos II (1846. Un verdadero renacimiento del agónico drama histórico se produce gracias a las obras de intención poítica escritas, entre otros, por Rubí. En ellas junto a la exaltación de la unidad patria frente a las injerencias extranjeras se preconizan nuevos valores democráticos basados en la libertad y en la justicia.

3. Este arquetipo de drama histórico de la segunda mitad del XIX es roto, entre otros, por Tomás Rodríguez Rubí, quien, a juicio de F. San Vicente: "no fue un dramaturgo romántico sino un puente entre el drama histórico, tan practicado por los románticos, y la alta comedia burguesa que llegará a dominar las tablas a mediados de siglo. Rubí ocupó una posición central en la actividad teatral del XIX. En su época se le consideró relevante competidor de Bretón, Gil y Zárate, Hartzenbusch, Rivas, García Gutiérrez, Zorrilla y Vega, en cuanto a su productividad y originalidad. San Vicente, F. "El teatro, (II): continuidad del drama histórico", en Historia de la Literatura Española. Siglo XIX,(I). Madrid. Espasa Calpe, 1997, p. 396. 
Arranca, por tanto la vida literaria de Rubí en aquel momento en el que la fuerza del romanticismo había decaído y en el que, a juicio de Jacinto Octavio Picón, un grupo de autores, entre los que se encuentra Rubí, "pensaron juiciosamente que la literatura dramática debe ser más que ninguna otra forma del arte la expresión del medio social en que se produce; comprendieron que la acción puede y debe desarrollarse con figuras contemporáneas, con asuntos del día, con pasiones favorecidas u hostigadas por la vida moderna y emprendiendo distinto derrotero, empleando procedimientos nuevos o manejando artificiosamente los antiguos, vinieron a formar un grupo de autores dramáticos que por sus buenas cualidades o sus errores representan en sus obras la sociedad española de estos últimos años con mayor fidelidad que pudieran hacerlo las historias más juiciosas o los diarios de sesiones mejor ordenados." ${ }^{4}$

Nace Rubí en Málaga el 21 de diciembre de 1817 en el seno de una familia acomodada. Fue hijo de un comandante de Artillería Naval que por su profunda ideología liberal fue perseguido por el régimen absolutista. Esta circunstancia acarreó a nuestro autor una infancia llena de vicisitudes y de continuos traslados familiares como consecuencia del acoso político al que su padre fue sometido. En esta defensa a ultranza que su padre hizo de sus ideales políticos hemos de ubicar la semilla de lo que más adelante se convertirá en la personal y decidida dedicación del dramaturgo a la actividad pública. Desde niño Rubí sufrió el azote de la intolerancia, así como la persecución por parte de los defensores del poder establecido. Hechos que dejaron en su alma una profunda huella, la cual tratará de borrar con todas sus fuerzas llegado el momento ${ }^{5}$.

\footnotetext{
4. Picón, Jacinto Octavio. "D. Tomás Rodríguez Rubí", en Autores Dramáticos Contemporáneos y Joyas del Teatro Español del XIX. Tomo II. Madrid. Imprenta Fortanet, 1882, p. 69.

5. Dada la importancia que para Rubí hubo de tener la persecución política a la que se vio sometido su padre a causa de sus ideas liberales, nos parece oportuno consignar el periplo vital que dicha persecución provocó. Al mismo hace referencia el cronista anónimo, quien nos indica que: "de 1820 a 1823 desempeñó - el padre de Rubí - la Contaduría de Crédito Público y fue comandante de la Milicia Nacional en Málaga. Persona de ideas liberales que fue perseguido y encarcelado tras el restablecimiento del régimen absoluto. Se le abrió proceso por sus opiniones liberales, y dadas las circunstancias el fallo de tribunal era claramente condenatorio. Ante una condena a muerte casi segura, y gracias a les gestiones de sus muchas amistades logró escapar de la Torre de Tirilo. Con presteza se trasladó de Málaga a Granada, ciudad en la que volvió a ejercer como Contador del Crédito Público. Acosado por la policía tuvo que trasladarse a Jaén con la ayuda de su inestimable colaborador y amigo Juan Bautista Erro. No pudo Erro darle amparo por más tiempo y le proporcionó otro destino con visos de destierro, en este caso como Administrador de Rentas en Melilla, en 1829. A los pocos días de pisar suelo melillense, debido a las muchas fatigas pasadas y su quebrantada salud, murió cuando Rubí contaba tan sólo con trece años." Cfr. Cronista Anónimo, " Semblanza de Tomás Rodríguez Rubí", en Revista de Teatros, $\mathrm{n}^{\mathrm{O}}$ 672, (1.12.1844)
} 
A causa de tanto cambio de domicilio, el autor malagueño adquirió su educación básica tal y como estas circunstancias anómalas se lo permitieron. En Granada estudió las primeras letras en el prestigioso Colegio de Santiago de manos de D. Miguel Urbina. En dicho Centro escolar permaneció con gran aprovechamiento hasta 1827 y de su condición de buen estudiante nos da testimonio su amigo Antonio Ferrer del Río al indicarnos que "en este colegio siguió perfeccionándose en latín y destacando en los exámenes públicos, tanto por su aplicación, como por la prontitud y desembarazo con que satisfacía las cuestiones y recitaba sus discursos. La Sociedad de Amigos del País lo admitió en su seno como especial recompensa"6.

Muerto su padre en Melilla, Rubí regresa a Málaga con su madre y allí es testigo de una de las más crueles escenas de la historia de su tiempo: el fusilamiento de Torrijos, Flores, Calderón, Golfin y otros. Fatídico acontecimiento que golpeó de nuevo el alma de nuestro autor, quien junto a su madre de traslada a Madrid en busca de mejor fortuna. Siendo un adolescente se coloca Rubí como escribiente en varias dependencias y oficinas, en ellas es muy apreciado por su conducta, amor al trabajo y elegancia de su letra. En estos momentos de penuria económica se cruzó en su vida D. Cipriano de Guzmán, Conde de Teba y Montijo, antiguo amigo de su padre, quien, tal como sostiene Ana María de Burgos, "toma al huérfano bajo su protección, dándole un puesto en el archivo de su casa. Su estancia allí hubo de ser en extremo beneficiosa para el joven Rubí, por haber sido durante largo tiempo el punto de reunión de la mejor sociedad madrileña. Ya entonces, cuando todavía era muy pequeño, se dedicaba en sus ratos de ocio a la lectura de la Historia y al estudio de los modelos del teatro antiguo, lo que revelaba su inclinación por las letras. ${ }^{17}$ Fue en esta época de acogimiento bajo la tutela del Conde de Teba cuando Rubí comenzó sus escarceos literarios escribiendo unos "mal llamados versos" que trataban de temas legendarios, así como el poema La inspiración para el diario No me olvides. Dicho poema fue rechazado por Salas y Quiroga, director del citado periódico, por su escasa calidad literaria.

No se desanimó nuestro escritor tras los primeros fracasos y continuó con sus colaboraciones poéticas en la prensa madrileña, las cuales se insertaban en las páginas de El Alba, así como en las columnas de Las Musas (1837), El Laberinto (1844-1845), Semanario Pintoresco Español (1840-1848), Los españoles pintados por sí mismos (1845), La Ortiga (1849), El Clamor (1845) y El Sur (1856).

6. Esta formación básica la completó en Jaén con la adquisición de los conocimientos necesarios en matemáticas, francés y dibujo.

7. De Burgos, Ana María. "Vida y obra de Tomás Rodríguez Rubí" en Revista de Literatura, 23, (1963), p. 66. 


\section{VÍCTOR CANTERO GARCÍA}

Una dilatada experiencia periodística que culmina con el desempeño del cargo de

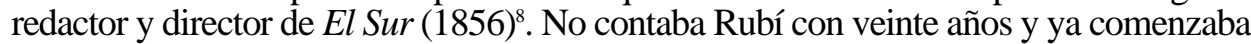
a abrirse paso en los ambientes literarios madrileños gracias a las recuperación del Liceo Literario. Y decimos recuperación porque lo que comenzó como Instituto o Liceo Literario vino a convertirse en un teatro casero, caduco a fuerza de decadente. El nuevo Liceo se estableció en el magnífico Palacio de Villahermosa, en cuyos espléndidos salones, a veces con asistencia de la Reina, la Familia Real, el Gobierno y el Cuerpo Diplomático extranjero se celebraban aquellos inolvidables "jueves del Liceo", de los que habrían de surgir tantos nuevos ingenios. Según el nuevo reglamento del Liceo, quien aspirase a ser socio de su sección literaria tenía que presentar una obra a dictamen de un tribunal o junta calificadora. Rubí escribió al efecto El Águila, una composición que es calificada por Antonio Ferrer del Río como "regular en sus formas, fácil en sus versos; cuyas descoloridas imágenes y languidez de entonación se armonizan mal con lo elevado del asunto"110. Hubo empate en la votación del jurado y se le dio al aspirante una nueva oportunidad. En esta ocasión presentó nuestro autor una leyenda titulada Un recuerdo de la Alhambra, que por su ameno giro y fluidez en el lenguaje le valieron la deseada admisión. Nombrado socio del Liceo en 1838 se aplicó aún más al estudio de la Historia y de la Literatura. En dicha Institución Cultural compartió veladas y amistades con sus primeros y más íntimos amigos: R. de

8. Esta labor periodística es destacada por Amparo Quiles Faz, quien nos indica que: "el propio Rubí nos dejó constancia de su opinión sobre la importancia de la prensa en su comedia de costumbres La familia, (1866)" Cf. Quiles Faz, Amparo. "Y se abrió el telón...concepto e imagen de la mujer en las comedias de Tomás Rodríguez Rubí", en Actas del I Congreso de Historia y Crítica del Teatro de Costumbres. Ayuntamiento del Puerto de Santa María, 1995, p. 167-168.

Efectivamente, en dicha comedia, Sabino, el hijo de la familia, entregado a la locura de ser publicista y redactor, afirma que:

Santos: "Amo, admiro y reverencio la prensa moral, la docta; la que reprende y no agravia, la que enseña y no acogota.

Réplica: Tú con esa facundia que te devora escribes...ips!...por llenar sin advertir que algún día vendrá en que contigo a solas con más saber y experiencia querrás dar tu sangre toda por borrar...iy no podrás!" el papel que hoy emborronas"

Cf. Rodríguez Rubí, Tomás. La familia. Comedia original en tres actos y verso. Madrid. Imprenta de José Rodríguez, 1866, p. 51

9. A ello alude Jacinto Octavio Picón, quien nos señala que "en el Liceo de aquellos días como en nuestro Ateneo, se dieron a conocer hombres eminentes, y los poetas tuvieron una tribuna, en torno de la cual se apiñaban para oírles y admirarles los elementos más ilustrados de la Corte: Bretón, Ventura de la Vega, Hartzenbusch, Espronceda, Zorrilla, Pastor Díaz, Segovia, García Villalta, Larra, García Gutiérrez, José María Díaz, Campoamor, Gil y Zárate, el Duque de Rivas, aseguraban una y otra noche, el triunfo de la nueva escuela, ya dando a conocer sus propias obras, ya aplaudiendo las ajenas, y luego el público sancionaba aquellas reputaciones en los teatros del Príncipe o la Cruz, donde trabajaban Bárbara y Teodora Lamadrid, Concepción Rodríguez, Latorre, Romea, Valero, Arjona, Guzmán y tantos otros que han muerto sin sucesión legítima de su valor dramático." Jacinto Octavio Picón, Art. cit., p. 70.

10. Antonio Ferrer del Río, Art.cit., p. 2 
Campoamor y A. Ferrer del Río, al mismo tiempo que se integró en la nueva generación literaria formada, entre otros, por Bretón, Ventura de la Vega, Espronceda, Zorrilla, Larra y García Gutiérrez.

Preparado estaba ya nuestro dramaturgo para dar el salto a la fama y lo dio con la publicación de sus Poesías Andaluzas, $(1841)^{11}$. Con este retrato de la las costumbres y de la vida popular del sur de España obtuvo un sonado éxito, tras el cual se le abrieron las puertas de los editores y empresarios. Ya en 1839 había escrito su primera comedia titulada Del mal el menos. En aquellos momentos dirigían la empresa teatral de Madrid los señores Lombía y García Luna. Surgidas las primeras dificultades para representar su obra, tuvo la suerte de conocer al famoso actor Julián Romea en los salones del Liceo. El actor le prometió representar su obra, la cual pocas semana más tarde se estrenó en el Príncipe y el público aplaudió con tanto estruendo que el autor tuvo que salir a escena. Desde este momento hasta 1871 Rubí no dejó de escribir para el teatro, cosechando una serie ininterrumpida de éxitos en todos los géneros. Ya en 1857 contamos con una nota de prensa en La España, en la que se indica que: "con La escala de la vida son ya 59 los dramas escritos por Rodríguez Rubí"12

Tanta pública aclamación llamó la atención de aquellos amigos suyos que ya hacía tiempo militaban en política y convencido por ello ingresó nuestro autor en el partido moderado. A los treinta años ya era Diputado por varios distritos, comenzando a hacer carrera política de la mano del Conde de San Luis, Ministro de la Gobernación en el Gabinete de Isabel II. Sus relaciones con el Gobierno de turno y con Palacio fueron siempre muy estrechas, sobre todo a partir de la representación de su drama Isabel la Católica (1850) en el Teatro Español. La Reina le honró con su presencia en el estreno y por lo acertado de su contenido le concedió el diploma de Comendador de Carlos III. El hecho de que fuese un protegido del Conde de San Luis propició que los favores de la Reina hacia su persona fueran continuos, así en 1852 le concedió una pensión vitalicia de 30.000 reales anuales, al mismo tiempo que le encargó de que reuniera los materiales necesarios para escribir una Historia General Filosófica de la Monarquía Española, que nunca llegó a escribir ${ }^{13}$.

Es acorde con nuestro propósito el destacar aquí la importancia de su carrera política, pues de ella dependerán las intenciones de los dramas que más adelante hemos de analizar. Desde 1853 Rubí desempeñó cargos públicos, tanto durante el reinado de Isabel II como durante la Restauración ${ }^{14}$. Ese mismo año es nombrado

11. Un conjunto de poemas, que en opinión de Salvadora Agudo Pérez: "tienen un tono jocoso y festivo, aunque no falten los temas graves. En realidad son un conjunto de cuadros de costumbres en verso que van desde la leyenda a la poesía cantable. Sobresalen La venta del jaco, La buena ventura, entre otras.". Cf. Agudo Pérez, Salvadora. "Rubí", en Revista Jábega. Málaga. Diputación Provincial, 1979, p. 59

12. La España, (7.4.1857)

13. Cf. Archivo Histórico Nacional. Expediente de Tomás Rodríguez Rubí. Ministro de Ultramar. Intendente de Hacienda en Filipinas. Legajo 2.433, $\mathrm{n}^{\circ} 85$

14. En esta combinación de la profesión literaria con la actividad política sigue nuestro autor los pasos de otros compañeros, tal es el caso de Francisco Martínez de la Rosa, R. de Campoamor, Nuñez de Arce y López de Ayala. 
Vocal de la Junta de Teatros y Diputado a Cortes por Cuenca. En 1854 es nombrado Oficial Mayor del Ministerio de Gobernación. En 1858 es nombrado Jefe de Sección y Director General de Bienestar y Salud en dicho Ministerio. Además ocupó interinamente las Direcciones Generales de Administración de Correos y la de Establecimientos Penales. Si bien en el desempeño de todos estos cargos supo cumplir adecuadamente con su cometido, mucho más polémico fue su nombramiento como Director del Teatro Español. Fue el propio Conde de San Luis quien lo puso al frente de un experimento teatral con el que se pretendía dar un impulso definitivo a las reformas teatrales promovidas en 1849 desde el Gobierno. Tal proyecto gubernamental consistía en transformar el teatro del Príncipe en un Teatro Nacional que simbolizase los esfuerzos de las autoridades españolas por sacar al teatro del estado de abandono que sufría. En un primer momento se puso a Ventura de la Vega al frente de esta propuesta. Este nombramiento no fue del agrado de Rubí, quien desde las páginas de La Ortiga acusa a Vega - no sin razón - de aprovecharse del puesto para escenificar muchas de sus traducciones, de organizar una claqué que aplaudiera sus obras, de repartir entradas gratuitas entre sus amigos y de presunta malversación de fondos públicos. Nuestro autor acusa a Vega de no contar todos los ingresos de taquilla dentro de la ganancias brutas del día, lo cual podía afectar negativamente a los sueldos de los autores y actores, pues estos cobraban en función de los ingresos brutos. Además llegó a menospreciarlo, calificándolo como: "un señor infinitamente pequeñito, caprichoso y depósito de todas las pasioncillas pequeñas." ${ }^{15}$ Vega sucumbió ante tales ataques.

Eliminado su contrincante, no se encontró obstáculo para el nombramiento de Rubí al frente del Teatro Español. Desde su toma de posesión intentó superar la gestión de sus antecesores pero las circunstancias se le pusieron en contra. Por un lado, los autores, encabezados por Julián Romea, estaban en contra de tal experimento teatral y al comienzo de la temporada de 1849 abandonaban el Español y se trasladaban al Variedades. Por otro, era notoria la falta de obras de calidad y envergadura para sostener con dignidad tal intento, a la par que resultaba imposible competir con los demás teatros de Madrid. Todo ello hizo que "los buenos propósitos del Conde de San Luis se estrellasen contra la apatía del público que dio en no ir al teatro del Príncipe ( ahora Español), apatía que tenía su explicación en la falta de novedades que ofrecía el espectáculo. "16 Rubí asumió su fracaso como gestor, y tal como nos precisa W. F. Smith, el 10 de julio siguiente "the government had recognized its failure, had abandoned the attempt

15. La Ortiga, (1849), p. 207

16. Díaz Escobar, Narciso y Lasso de la Vega, Francisco de P. Historia del Teatro Español. Tomo II. Barcelona, 1924, pp. 25-28 
at directing the theatre and had invited the dramatic authors to undertake the task. ${ }^{17}$ Tras una segunda temporada teatral totalmente desastrosa, el Gobierno dictó una Real Orden el 19 de mayo de 1851 por la que el teatro Español se disolvía.

No acaba aquí la participación de nuestro autor en los asuntos del Estado, pues en 1866 es nombrado Intendente General de Hacienda en Filipinas. Vuelve a España en 1868 y se le nombra Ministro de Ultramar. Ya por entonces comenzaba a respirarse un clima revolucionario y la situación de Isabel II era cada vez más delicada. El 19 de mayo de ese mismo año González Bravo disuelve las Cortes y la Reina parte para el exilio en Francia, acompañada por Rubí, entre otros cargos de su confianza. Tras la Restauración fue nombrado Delegado Regio de Hacienda en Cuba y poco después ocupó una Vicepresidencia en el Consejo de Estado.

Tanta responsabilidad política, que siempre supo compaginar con su dedicación literaria, tocó a su fin el 14 de agosto de 1890. La noticia de su muerte impresionó sobremanera a la ciudadanía española y de ella se hizo amplio eco la prensa con comentarios como el que aquí se transcribe:

"Don Tomás Rodríguez Rubí deja un nombre ilustre, una reputación intachable de honradez y gran humanidad, sus ideas e inclinaciones viven palpitando en las escenas de sus obras. No se le ha hecho uno de esos entierros de artificio, con oraciones, coronas de flores y marchas fúnebres en el teatro, sino una modesta, cariñosa y amistosa despedida, conforme a sus deseos." ${ }^{18}$

\section{Los desvelos de Rubí por reformar el teatro decimonónico: bases teórico- prácticas para el ejercicio teatral}

Antes de comenzar nuestro análisis de esa parcela del drama histórico rubiniano que hunde sus raíces en la experiencia de nuestro autor como gestor de la cosa pública, es imprescindible que consideremos de forma detenida su propia concepción del arte dramático y sus preocupaciones por mejorar la práctica del mismo. El drama histórico de intención política que aquí nos ocupa,

17. Smith, W. F. "The contribution of Rodríguez Rubí to the dramatic reforms of 1849", in Hispanic Review, (XVI), 1948, p. 313

18. La Ilustración Española y Americana, (14.8.1890).

En este mismo tono escribe su reseña el cronista de La Amenidad, quien nos destaca de Rubí que: "entre las distinguidas cualidades que lo adornan, se cuenta una que da más y más realce a su bien merecida reputación, y es su proverbial modestia.; Loor inmarcesible a tan distinguido poeta!, i gloria también a la hermosa ciudad, que tiene la dicha de contarle en el número de sus hijos!. Cf. La Amenidad, (Periódico General de Literatura, Modas y Teatro), n 11, (12.1.1845), pp .85-86 
al igual que el resto de su producción teatral, obedece a unos principios y a unas orientaciones técnicas que el propio autor dejó con claridad expuestas en su discurso de ingreso a la Real Academia Española, titulado: "Excelencia, importancia y estado presente del teatro" (1860). En dicha disertación Rubí nos ofrece su diagnóstico de los males que aquejan al teatro español de la segunda mitad del XIX, apuntando sus causas y proponiendo soluciones.

Concibe el dramaturgo el teatro como: "un espejo de las edades que pasan y de la edad que va pasando. Patrimonio del teatro son la sociedad y el individuo en todos sus estados, con todas sus virtudes, sus sentimientos, sus pasiones y flaquezas. En su limpio cristal, proyectados por la musa dramática, se reflejan los errores del hombre, los extravíos del entendimiento, la relajación de las costumbres, los caracteres sencillos, afectuosos, duros e incorruptuptibles." ${ }^{19}$ Este concepto del teatro como testigo fiel del acontecer social, en opinión de Jacinto Octavio Picón, acerca a Rubí a las tesis de la comedia moderna fundada en la observación del natural por el análisis de las costumbres o los caracteres. Dicha nueva orientación dramática sintió la necesidad de supeditar el vuelo de la imaginación a las exigencias de lo real; con ella los autores comprendieron que la escena contemporánea debe ser un espejo de la vida social donde la figura del autor queda pospuesta a las imágenes de la acción que refleje. Los dramaturgos estimaron conveniente que la personalidad del poeta permaneciese velada tras los caracteres que ponía en juego y fueron en gran parte, transigiendo con la aspiración del teatro de nuestros días que no puede seguir siendo dominio exclusivo de la fantasía.

En lógica consecuencia con esta concepción social del arte dramático, Rubí entiende el teatro como una verdadera escuela de costumbres cuando el arte dramático dogmatiza y reflejo de éstas, siempre que las retrata. Y como no existe entre ambas facultades incompatibilidad ni antagonismo, ni hay obra de autor que no tenga por objeto una enseñanza útil, resulta que el teatro, bien entendido, es, y forzosamente debe serlo, escuela, por las lecciones que se dan en él, y reflejo de costumbres, por el retrato que de ellas se hace. En este binomio teatro-sociedad, el primero no se impone a la segunda, y cuando la corrupción se apodera de ésta, el autor dramático, en su papel de retratista, tal como afirma Ana María de Burgos en alusión a Rubí: "no hace sino usar de los colores que la sociedad misma le sirve en su paleta." ${ }^{20}$

19. Rodríguez Rubí, Tomás. "Excelencia, importancia y estado presente del teatro", en Discursos leídos en las recepciones públicas de la Real Academia Española. Madrid. Imprenta Nacional, 1860. Fecha de ingreso: 17.6.1860.

20. Ana María de Burgos. Art. cit., p. 85 
A tenor de estos principios teóricos, parecería adecuado situar a nuestro autor lejos de los presupuestos del drama romántico, cuyas exageraciones siempre criticó. Sin embargo, este rechazo de los postulados románticos no debió ser tan radical, al menos así nos lo confirma W. F. Smith, al precisarnos que: "las relaciones de Rubí con la escuela romántica representan una de las mayores contradicciones de su teatro. Él se proclamó enemigo de esta escuela, ridiculizó sus excesos en parodias románticas en verso, fundó su teatro en una ausencia total de los principios románticos, pero pese a esto la fuerza y la huella del romanticismo están presentes en su tendencia al sentimentalismo y al efectismo."21 Ambigüedades ideológicas al margen, Rubí identificó con claridad los males que aquejaban a nuestro teatro, pero en modo alguno se dejó arrastrar por el pesimismo, pues, tal como él mismo manifiesta: "el teatro español no ha muerto, iporque no puede morir! ... en tanto que no se extinga el último destello del ingenio en la mente de los españoles. Y nada hay que pruebe de una manera más concluyente las fuerzas vitales de aquel, que el estado en que se encuentra."22 Una delicada situación de la que el autor culpa a la calamitosa circunstancias políticas del XIX, a la escasa protección legal que el Gobierno ha proporcionado al teatro y a la concepción del espectáculo teatral como un negocio lucrativo.

Consciente Rubí de que ante tal deterioro no era suficiente con el limitado auxilio de los poderes públicos, llamó la atención de las autoridades sobre esta crítica situación y colaboró con ellas en la redacción y aplicación de medidas legales que pusieran fin a la misma. El dramaturgo se ganó la voluntad del poder político, el cual nunca como entonces se preocupó por mejorar nuestra escena. Fruto de estos afanes de nuestro autor fue la decidida apuesta oficial por mejorar la situación económica de los autores y actores, por establecer sus derechos frente a los empresarios teatrales y traductores y por dignificar la profesión de actor, entre otras muchas cuestiones. En este mismo sentido, Rubí elaboró y presentó al Gobierno un Proyecto de Reglamento de Teatro para la ejecución de la Ley de propiedad intelectual de 10 de enero de 1879. En dicha propuesta de texto legal,

21. Smith. W. F. "Los dramas históricos en el teatro de Tomás Rodríguez Rubí" en Bulletin of Spanish Studies, 28,(1950), p. 222.

Una opinón que es compartida por Leonardo Romero Tobar, para quien Rubí forma parte de ese grupo de autores que empujados por las tendencias galofóbicas del momento repudiaron el romanticismo francés por considerarlo ajeno a nuestros intereses patrios. Dicha repulsa se manifiesta en: "la construcción de unos personajes optimistas, capaces de oponerse a los desdichados caracteres de los dramas franceses o al propio destino adverso que es afrontado por los personajes del teatro español con una alta dosis de patriotismo." Cf. Romero Tobar, Lonardo. Panorama del romanticismo español. Madrid. Castalia, 1994, p. 300.

22. Tomás Rodríguez Rubí. Art. cit., p. 436 


\section{VÍCTOR CANTERO GARCÍA}

el escritor recoge los aspectos más significativos que eran susceptibles de mejora en la actividad teatral del momento, a saber: "el primer capítulo tiene artículos referentes propiedad de las obras y traducciones extranjeras de obras dramáticas y musicales, así como las reglas para fijar los propietarios de dichas obras. El segundo capítulo trata de la admisión de obras dramáticas y musicales por las empresas de teatro, fijando ciertas condiciones que deberán ser observadas por los empresarios. En el tercero se establecen los derechos de representación de las obras dramáticas y musicales. El cuarto se refiere a las prohibiciones relacionadas con la venta de obras y fija que no es necesario la publicación para reclamar la propiedad intelectual. El último apartado lo dedica a las penalidades que sufrirán los infractores de dichas normas." ${ }^{23}$ Todas estas sugerencias fueron tenidas en cuenta por el Gobierno a la hora de redactar los textos legales que regularon el ejercicio teatral español a finales del XIX. ${ }^{24}$ Sin embargo, Rubí no se contentó con las aportaciones teóricas, sino que se aplicó de forma decidida a escribir y representar un gran número de dramas y comedias; siendo las de género histórico e intención política las que a nosotros nos interesan. La razón de esta especial inclinación de Rubí a componer piezas de crítica política se encuentra en su obsesión por convertir el teatro en un alegato contra la corrupción y el deterioro de la gestión pública. Tan aquilatada es esta mezcla de teatro y política, que

23. Ana $\mathrm{M}^{\mathrm{a}}$ de Burgos, Art. cit., p. 87

24. La implicación de Rubí en todos aquellos acontecimientos que se relacionan con la vida teatral de la época es recogida en las diferentes reseñas de la prensa. Entre ellas, destacamos las siguientes:

a. La Iberia, (15.6.1860): "Toma de posesión del académico Tomás Rodríguez Rubí".

b. La Nación, (3.7.1850): Anoche se reunieron para nombrar la comisión que debía dar las gracias al Gobierno en nombre de los autores, a los que se les ha concedido la mitad de los beneficios del Teatro Español. Los comisionados serán Hartzenbusch, Bretón y Rubí.

c. La Esperanza, (2.1.1859): "Los Señores Rubí, Hartzenbusch, Narciso Serra y Juan de la Rosa ponen fin a la cuestión que había entre los escritores D. Luis Mariano de Larra, al que se acusa de haber plagiado una obra de D. Enrique Pérez Escrich, y dice que La oración de la tarde y EI cura de aldea, son entre si distintas, aunque así en la una en la otra se usa el mismo recurso dramático para producir el desenlace."

d. La Época, (3.10.1865): "El jurado nombrado para el examen del drama Juan Lorenzo se compone de los Señores Bretón de los Herreros, Presidente y como vocales Hartzenbusch, Rubí, Ayala y Villargas."

e. La Esperanza, (15.1.1860): "La eminente actriz Dña. Matilde Díez se ha dirigido a alguno de nuestros escritores pidiéndoles nuevas obras, y ya están terminando dos los Señores Rubí y Luis Mariano de Larra. Ignoramos todavía cuáles son los títulos respectivos."

f. Diario de Avisos, ( 26.6.1841): "Galería dramática: Colección de poesías de los Señores José de Zorrilla, José de Espronceda, Rubí y Nicomedes Pastor Díaz." 
nuestro dramaturgo nos ofrece en estos textos verdaderos manifiestos con los que instruir a la ciudadanía acerca de los vicios y defectos que aquejan a la clase política ${ }^{25}$.

Tal transformación del teatro en tribuna política requiere una sutil aclimatación de los recursos del drama histórico a los fines políticos que el autor persigue. Dicha aclimatación realizada por Rubí proporciona a sus textos las siguientes características:

\section{a. El autor se sirve de la Historia como simple telón de fondo}

Tal como nos informa W. F. Smith, Rubí nunca tuvo interés por la Historia en sí misma, tan sólo supo utilizarla para traer a la escena hechos contemporáneos. Este tratamiento de lo histórico tiene lugar en Bandera negra (1847), La Corte de Carlos II (1846), Alberoni (1846), La rueda de la fortuna (1843) e incluso en Isabel la Católica (1850), considerado el último de sus dramas. Este uso interesado de los acontecimientos históricos sitúa a nuestro autor lejos de los principios y recomendaciones que en su día estableciera Francisco Martínez de la Rosa, según el cual todo autor de este tipo de obras debe saber que "cuando se trata de argumentos históricos la primera cualidad es la verdad de la imitación, pues aunque no se exija, y antes bien sea falta grave, reducirse a una copia servil, nunca debe perderse de vista la índole de semejantes composiciones. "26

25. Este intento por politizar el teatro no es exclusivo de Rubí, pues tal como nos señala David Thatcher Gies: "el drama histórico y/o político no era nada nuevo en la escena española, y los experimentos de los románticos con el teatro histórico -empezando por La conjuración de Venecia - ya eran claro indicio del atractivo que tenía la unión de atmósfera política y realidad contemporánea para el público de los años 30 y 40. Durante los últimos doce años el teatro había tenido un papel complementario (como ocurrió también en tiempos de la invasión napoleónica) de foro para el activismo político, convirtiéndose en punto focal de causas políticas, de exhortaciones para que el público de una u otra tendencia y de púlpito desde el cual se podía animar el espíritu de los concurrentes y recaudar fondos para una causa." Thatcher Gies, David. El teatro español en el siglo XIX. Cambridge University Press. Cambridge, 1994, p. 193

De esta atracción por los temas políticos participó Eusebio Asquerino, coetáneo de Rubí - que fue periodista y dramaturgo de manifiesta tendencia republicana. Asquerino escribió obras teatrales calificadas por García Castañeda como " dramas históricos de inclinación política ". En colaboración con su hermano Eduardo produjo varios dramas históricos con alusión a la situación del memento: Dña. Urraca (1838), Gustavo Vasa (1841), Españoles sobre todo (1844), Las guerras civiles (1849) y Las dos reinas (1853).

26. Martínez de la Rosa, Francisco. "Apuntes sobre el drama histórico" en Obras Completas. Tomo I. Madrid. Atlas, 1962, p. 390

A Rubí lo que de verdad le importa es servirse de los hechos históricos que tengan claro paralelo con los momentos políticos del presente, y en tal sentido: "this two comedias La Corte de Carlos II (1846) and Desde el humbral de la muerte (1847) do achieve it seem to do so incidentally, for the respective courts portrayed bore such strikinn resemblance historically to the court of Isabel II and the political issues involved were so closely analogous that there was no incentive to invention o distorsion." Cf. Smith W. F. "The contribution of Rubi to the development to the Alta Comedia", in Hispanic Review, X, (1942), p. 57 


\section{b.Los dramas histórico-políticos de Rubí repiten un patrón argumental predeterminado}

Todas las piezas incluyen un motivo recurrente: el nombramiento y cese del Primer Ministro o Ministro Universal. La trama argumental se centra en las pugnas y disputas de los candidatos por alcanzar el favor del Rey. En este combate político siempre vence el mismo prototipo de gestor público: el honrado, patriota, incorrupto; es decir, el que sólo se preocupa de proteger y engrandecer la gloria nacional.

Así sucede con el Conde de Peñaranda, el cual vence y supera a Nithard en Dos validos y castillos en el aire (1842). Lo mismo ocurre con la Marquesa de Torrecuso en relación con el Marqués de la Ensenada en La rueda de la fortuna. Por su parte el Conde de Medinacelli vence a D. Juan de Austria en La Corte de Carlos II y la Princesa de los Ursinos derrota al Cardenal Alberoni en Alberoni. Con estos simples recursos históricos Rubí desgrana en sus textos toda una serie de críticas contra las malas prácticas políticas. Nuestro autor pone en conocimiento del público los afanes de los cortesanos, nobles y burgueses por aprovecharse de sus influencias para medrar a costa de sus adversarios. En suma, los textos son un vivo reflejo de cuanto acontecía en la corte de Isabel II, en la que los abusos de poder y las arbitrariedades eran moneda corriente.

\section{c. Nuestro autor pretende que sus obras hagan renacer el teatro patrio frente a las modas extranjeras}

De acuerdo con lo que nos manifiesta Leonardo Romero Tobar, los dramas histórico-políticos de Rubí "pretenden el resurgimiento del espíritu nacional."27 A nuestro autor, como a gran parte de sus compañeros de generación, no le preocupa la exactitud de los datos sino su correlato con el momento presente. Un correlato con el que se pretenden dos objetivos; por una lado, acercar al espectador a los hechos políticos más inmediatos, mientras que, por otro, se busca a toda costa la exaltación de los valores patrios frente a las modas extranjeras. En este sentido, casi todos los autores ponen colofón a sus obras con una apología de la independencia e identidad hispanas ${ }^{28}$.

27. Leonardo Romero Tobar. Ob.cit., p. 300.

28. En esta misma dirección se insertan los dramas históricos de los hermanos Asquerino, Víctor Balaguer, Manuel Fernández y González, Carlos García Doncel, Ramón de Navarrete, Luis Olona, Francisco Luis de Retes, Tomás Rodríguez Rubí, Tamayo y Baus o Luis Valladares, entre otros. 


\section{d. En sus dramas histórico-políticos Rubí se gana el favor del público y se asegura el éxito}

Cierto es que gran parte de estos textos no resisten un análisis literario riguroso, pero no lo es menos que, tal como sostiene Ana María de Burgos, con ellas: "Rubí supo ganarse al público y con cada nueva representación cosechó un nuevo éxito. ${ }^{129}$ ¿ Cómo lo logró?. Nuestro autor acertó al presentar al público hechos de fácil comprensión con un lenguaje accesible y sencillo. En todos los casos se las ingenió para despertar la curiosidad del espectador por medio de caracteres populares, próximos y nada estilizados. Con todos estos ingredientes elaboró nuestro dramaturgo unas piezas que le proporcionaron el favor del público y de la prensa.

\section{Del pensamiento político a la práctica dramática: análisis de los contenidos políticos de sus dramas}

Hasta aquí hemos constatado que Rubí quiso convertir el escenario en foro político. Ahora nos corresponde constatar cómo llevó a la práctica dicha conversión. Dejamos a un lado la calidad literaria de los textos y nos centramos en descubrir la habilidad del autor para presentar en escena aquellos hechos históricos que tenían su directa equivalencia en los vaivenes políticos de la corte de Isabel II.

\section{a. Isabel la Católica (1850)}

Iniciamos nuestro recorrido con una de las piezas, cuyo éxito facilitó la entrada de Rubí en los círculos políticos. Comenzamos por ella porque sus contenidos se someten a la verdad histórica mucho más que el resto de los textos que vamos a analizar. Así nos lo ratifica Menéndez y Pelayo, para quien la intención historicista de Rubí en esta obra es clara "al presentarnos a un Gonzalo de Córdoba enamorado de la Reina. ${ }^{130}$

\section{Argumento de la obra:}

Pretende el autor concentrar en un drama de tres partes y seis jornadas todo el reinado de Isabel la Católica. Como es natural, un periodo tan amplio de estudio

29. Ana $\mathrm{M}^{\mathrm{a}}$ de Burgos, Art. cit., p. 101.

30. Menéndez y Pelayo, Marcelino. Estudio sobre el teatro de Lope de Vega. Tomo V. CSIC. Madrid, 1949, p. 334 


\section{VÍCTOR CANTERO GARCÍA}

tan sólo puede ser tratado de forma superficial. Dedica la primera parte a las guerras de sucesión, por medio de las cuales se allana el camino a la monarquía absoluta. En la segunda nos presenta la conquista de Granada con la que se completa la recuperación de España; mientras que en la tercera nos ofrece la conquista del Nuevo Mundo como símbolo de la expansión del Imperio. Estas gestas se le presentan al público por medio de una trama en la que predominan las intrigas cortesanas, las discusiones políticas entre Isabel y Fernando por la ostentación del poder absoluto y los amoríos de Gonzalo de Córdoba y la Reina.

2. Descripción de los contenidos de claro alcance y significación política:

Al encabezar nuestro autor el texto con una larga y meditada dedicatoria a Isabel II, sabe muy bien lo que hace. Su intención es establecer un claro parangón entre ambos reinados, el cual ya se inicia con la similitud de los nombres y se hace más explícito al señalar Rubí a Isabel II como: "digna sucesora del nombre y de las glorias de la egregia Señora, que en medio del choque de las armas y las convulsiones políticas de su época, tendió una mano protectora a los establecimientos de buenas letras y a los asilos de caridad."131

Se inicia la acción del drama en el Real Alcázar de Segovia, en cuyos aposentos nos presenta el autor a Isabel la Católica adornada con todas las virtudes cristianas: bondad, caridad y comprensión:

Reina: $\quad$ "Esa es la caridad!, esa la fuente de los eternos bienes celestiales. ¿Qué bien habla el apóstol a la mente y al pobre corazón de los mortales!

Beatriz: Es verdad, es verdad...pero ¡Señora! ¿aún no habéis advertido...?" $\left(I, 1^{a}, 14\right)$

Ella reina y confía en que sus cortesanos y pajes hagan de Castilla-León un reino fuerte y no dividido por luchas internas y de intereses como ella lo heredó:

Reina: $\quad$ "... si a los mayores de estos
que grandes los verás mañana,
tendieran una vez su regia mano
y agruparan sus timbres y blasones
en rededor del trono castellano,

31. Rodríguez Rubí, Tomás. Isabel la Católica. Madrid. Imprenta de S. Omaña, 1856, p. 1. Dedicatoria. A partir de aquí todas las citas de esta obra pertenecen a la misma edición. 
no me hubieran legado, Beatriz mía, tan pobre y destrozada de Castilla y León la monarquía." $\left(I, 1^{a}, 15\right)$

He aquí una directa alusión a las luchas intestinas que se suceden en la corte de Isabel II. Peleas y pugnas con las que cada bando político pretende imponer a la Reina el consorte que más le interesa.

Una ingenua confianza, pues todo el texto es una clara muestra de las disputas e intrigas de los nobles y cortesanos por impedir que la reina ostente un poder absoluto. Unos obstáculos que la monarca pretende vencer con el auxilio divino:

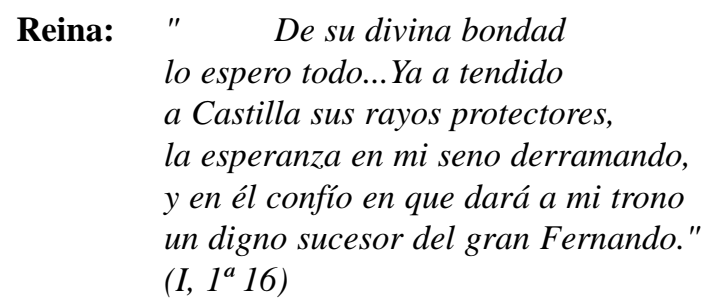

Sin embargo, estos desvelos de Isabel por hacerse con el trono contrastan con las protestas de Fernando, quien se siente débil y humillado por los castellanos que no lo aceptan como rey.

$\begin{array}{ll}\text { Reina: } & \text { ¿Fernando! ¿ } \quad \text { Qué os sucede? En vuestro rostro } \\ & \text { iFero el enojo y el dolor se pintan. } \\ \text { Rey: } & \text { Que aquí vuestros nobles castellanos } \\ & \text { con su orgullo y sus leyes, mortifican } \\ & \text { mi augusta dignidad, y parto lejos } \\ & \text { antes de que apuren la paciencia mía." } \\ & \left(I, 4^{a}, 27\right)^{32}\end{array}$

Estas quejas están justificadas, pues la no aplicación de la Ley Sálica conlleva que el poder recaiga sobre Isabel en detrimento de Fernando:

Reina: "Además, don Fernando, no olvidemos que en la cuna descansa nuestra hija... nuestra esperanza y única heredera,

32. Algo similar ocurre con Francisco de Asís, quien será esposo oficial de Isabel II, pero no tendrá ningún poder efectivo. 
y si en algo esas leyes se varían, no podrá recoger nuestra coronas." $\left(I, 4^{a}, 28\right)$

Toda una clara alusión al derecho de las mujeres a ocupar el trono en las mismas condiciones que los hombres:

Reina: $\quad$ ¡OOh...si abdicara yo...mis sucesoras despojadas del cetro se quedarían... y no es justo... las hembras también pueden con gloria gobernar la monarquía." $\left(I, 4^{a}, 29\right)$

No puede ser más directa la defensa del reinado de Isabel II, quien supo recompensarle con creces por este apoyo incondicional al derecho femenino al ejercicio de poder.

Vueltos al texto, no le convencen a Fernando las razones legales y deja Castilla camino de Aragón. Los conspiradores presionan a la reina, pero ella se siente con fuerzas suficientes como para defenderse sola de tantos enemigos:

$\begin{array}{ll}\text { Reina: } & \text { ¿ } \quad \text { Sois vosotros aquellos segovianos } \\ \text { de tan claro blasón y nombradía.... } \\ \text { los que me alzaron sobre el trono un día, } \\ \text { los que batieron en mi honor sus manos? } \\ \text { ¿ Do fue vuestra lealtad, vuestra bravura? } \\ \text { ¿prestáis a la traición fuertes oídos... } \\ \text { y en el silencio de la noche oscura } \\ \text { mi palacio asaltáis como bandidos? } \\ \text { ¡Miserables!... Segovia de rodillas } \\ \text { ante la Reina de las dos Castillas! } \\ \left(I, 8^{a}, 35\right)\end{array}$

Asistimos a toda una proclamación del poder real, la cual es toda una apología del poder monárquico de Isabel II, a quien apoyó en todo momento y a quien acompañó en su exilio ${ }^{33}$. Volverá Rubí a la escena política española con motivo

33. Tal como nos indica Ana $\mathrm{M}^{\mathrm{a}}$ de Burgos: "cuando arreciaba el clamor revolucionario, el 30 de septiembre de 1868 salía la reina Isabel II para Biarritz donde fue recibida por los emperadores franceses. Rubí salió más tarde para Francia con la intención de acompañar a la reina en su destierro. Dado que en algunos periódicos madrileños se murmuró acerca de esta repentina ausencia, tachándola de fuga, Rubí volvió inmediatamente a la corte y se dedicó a visitar los sitios más públicos de la capital con en fin de dejarse ver." Cf. Ana Ma de Burgos. Art. cit., pp. 74-75. 
de las negociaciones con el partido alfonsino y dado que no cuajaron las gestiones de Serrano, duque de la Torre, como la reina quería, será Cánovas quien el 22 de agosto de 1873 sera nombrado jefe definitivo del partido alfonsino con plenos poderes otorgados por la familia real.

3. Acogida de la obra por la crítica y el público:

Tal como nos precisa Ricardo Navas Ruiz, "Isabel la Católica pertenece al tipo de dramas históricos de exaltación patriótica que conlleva un retrato moral del personaje y un estudio de las implicaciones para la modernidad. Esta pieza trata del glorioso pasado imperial y con ella cosechó un notable éxito. "134

Mucho más completa es la crítica que nos ofrece W. F. Smith, el cual considera que el éxito de Isabel la Católica en la temporada 1849-50 vinculará definitivamente a Rubí con el Teatro Español El estreno de la obra fue toda una fiesta y contó con la presencia de Isabel II, a quien agradó mucho el contenido de la pieza. Para la lectura pública del texto el autor reunió a una audiencia selecta en el Palacio Real. Al final del acto la reina la concedió la Cruz Suprema de Carlos III. El público, impaciente por asistir al estreno, vio satisfechos sus deseos el 29 de enero de 1850. El éxito fue total y al final de la representación Rubí fue aclamado con "bravos" y se le arrojaron guirnaldas. Noche tras noche la pieza fue cosechando éxitos, tanto es así que "the immediate proceeds of the play, according to Rubí's own estimates, amounted to 56,000 reales. In addition Rubí was given a premium of 500 duros specified by law for the best dramatic production of the year and there was settled on him by the Commisary of the Crusade, a yearly pension of 400 duros on the grounds of the play, by the elevation of the tone, han contributed to the advanced of the cause of religion. ${ }^{135}$

Un éxito que es también destacado por E. Caldera, para quien Rubí "introduce en la obra escenas de gran efecto espectacular (una turba de caballeros insurrectos, un campo militar) y personajes famosos como Colón, Gonzalo de Córdoba, Boabdil, además de los Reyes Católicos, con una Isabel enérgica y un Fernando indeciso y sin personalidad, según los tópicos tradicionales que correspondían a las expectativas del público." ${ }^{136}$

34. Navas Ruiz, Ricardo. El Romanticismo español. Madrid. Cátedra, 1982, p. 400.

35. W. F. Smith. "The contributión of Rubí to the dramatic ..." Art. cit., p. 317.

36. Caldera E y Calderone A. "El teatro español del XIX" en Historia del teatro en España. Tomo II. Madrid. Taurus, 1988, p. 518. 


\section{b. La Corte de Carlos II (1846)}

No prosiguió Rubí en su exaltación del poder monárquico más allá de Isabel la Católica, pues en el resto de sus dramas histórico-políticos nos ofrece una radiografía crítica y mordaz de la degeneración, el vicio, los errores, las pugnas, las intrigas, los ataques y las luchas internas de quienes hacían de la conquista del poder y del derrocamiento de los reyes su objetivo esencial. Una clara muestra de ello la encontramos en La Corte de Carlos II, comedia en dos partes y seis cuadros, en la que, a juicio de David Thatcher Gies: "Rubí repite la fórmula de presentación de los hechos, de tal forma que sirvan de ejemplo y de lección para los tiempos presentes. Pero en este caso dicha fórmula le causó graves problemas al traspasar los límites de la corrección política. ${ }^{137}$ Las autoridades le acusan de escribir un texto contrario a sus intereses y tras la lectura pública el texto fue prohibido.

Muy mal le sentó a Rubí esta prohibición, tanto que en la cabecera de la obra escribe una larga nota en la que expresa al público las razones de su malestar. En dicha nota tacha la retirada de su obra de ataque a la propiedad del escritor y a la libertad de pensamiento, a la par que califica a quien lo delató de "Judas con alta capacidad político-literaria, que abusando de la inmerecida confianza que se le había dispensado, con bastarda oficiosidad dejó el salón de la lectura y se fue a esparcir la alarma a regiones elevadas, llamando la atención de las autoridades sobre lo que he estado muy lejos de imaginar, porque yo en esta comedia no quiero decir más que lo que digo." 38

\section{Argumento de la obra:}

Algo especial contenía el argumento de esta obra cuando escoció tanto a los defensores del poder absoluto. Nos presenta el autor la corte de Carlos II como el lugar en el que se dan cita todo tipo de intrigas y tretas con el único objeto de alcanzar el favor real y lograr el nombramiento de Ministro Universal. De un lado, entra en escena el Duque de Medinacelli, aliado del poder francés; y de otro, el Condestable de Castilla, que sigue los dictados de la Casa de Austria y cuenta con el apoyo de Ana María, la Reina Madre. Con gran habilidad el Duque conquista la voluntad del monarca, el cual renuncia al matrimonio impuesto con la Archiduquesa de Austria y elige por esposa a Luisa de Borbón, en contra de los intereses políticos de la Regente, que es quien manda y dispone en la corte.

37. David Thatcher Gies. Ob.cit., p. 233

38. Rodríguez Rubí, Tomas. La Corte de Carlos II. Madrid. Imprenta de Antonio Yentes, 1846, p. 2. Nota explicativa al público. A partir de aquí todas las alusiones a la obra son de la mima edición. 
No podemos encontrar un paralelo más exacto con la situación que por entonces se vivía en la España isabelina. Rubí lleva a las tablas esta obra justo cuando los ánimos internacionales estaban más exaltados con motivo del próximo matrimonio de Isabel II. Entre la facciones que maniobraban por sacar provecho del evento se encontraban los liberales, que con apoyo británico, proponían como consorte a D. Enrique, el hijo más joven del Infante D. Francisco. Por su parte, los moderados, con respaldo francés y María Cristina a la cabeza, apostaban por D. Francisco de Asís, un joven frívolo y disoluto. Las disputas fueron tan violentas que el propio Narváez se vio obligado a dimitir como Primer Ministro en abril de 1846.

Rubí, situó la acción de la obra en 1679, pero no por ello dejó de aproximarse demasiado al punto sensible de la cuestión, pues la Ana María del texto es la Regente en la realidad. Al igual que aquella, María Cristina conspira sin sutileza para que triunfe la facción francesa y las alusiones a su poder absoluto y a sus innobles intenciones son más que evidentes. Pagó nuestro autor cara su osadía, pero la prohibición de representar la obra no mermó su popularidad.

\section{Descripción de los contenidos de claro alcance e intención política:}

Se entremezclan en la obra las relaciones amorosas y las ambiciones políticas. De un lado el Duque de Medinacelli está enamorado de Engracia, sobrina de Ana María. El Duque es retratado como el personaje más astuto de la corte, pues logra que sus propósitos pasen inadvertidos, consigue provocar la conjura contra D. Juan José de Austria, hermanastro del rey, y al final se hace con el cargo deseado. Por otro, el Condestable de Castilla, quien se alía con Ana María, la Reina Madre, para lograr que el monarca le nombre su Ministro, en sustitución del finado D. Juan de Austria.

El retrato que el autor nos ofrece del Duque es por sí mismo toda una lección de inteligencia política:

Duque: $\quad$ iQué poco en el Real Palacio
el Ministro Universal,
el altivo don Juan de Austria,
a estas horas pensará
que en una casa harto humilde
del más modesto arrabal
de Madrid, se abre una mina
que pronto reventará!
Y no es fácil en la Corte
de mi puedan sospechar...
de mí, que entre todos


paso por el hombre más glacial e indiferente de España."

$\left(I, 4^{a}, 16-17\right)$

Tal astucia le lleva a promover la conjuración contra el favorito y culpar de la misma a su rival, el Condestable. Los conjurados exponen al Duque las quejas del pueblo y de la tropa por el gobierno despótico que ejerce D. Juan José de Austria:

Duque: "Esa misma es la señal. ¿Qué decís de la milicia?

Conjur. $1^{\circ}$ Que algunos jefes están indignados contra el Austria y tanta arbitrariedad". $\left(I, 4^{a}, 17\right)$

Y le exponen sus deseos de que Carlos II ocupe sin dilación el trono que le corresponde:

Conjur. $2^{\circ}$ "La Reina Madre en Toledo y aquí en palacio Don Juan ejerciendo por si sólo la suprema autoridad. Que el Rey Don Carlos segundo principie ya a gobernar, y que vuelva aquí su madre, es la opinión general." $\left(I, 4^{a}, 18\right)$

El parecido de la obra con la realidad política de momento era más que notorio. El poder político que María Cristina acaparó terminará imponiendo a Isabel II un matrimonio no deseado con Francisco de Asís. Esto es lo que censura Rubí con crudeza en la obra, en la cual Ana María no se sale con la suya; antes al contrario, es el bando opuesto el que le gana la partida.

Nada sospecha la Regente de lo cerca que está su desgracia:

Condestable: "Hace una hora que hablaros solicito y llegar hasta vos no me han dejado

Reina: Condestable, mostráis harta impaciencia ... pero calmad vuestra ansiedad, que ahora llevamos lo mejor de la partida: ya hablé a su majestad y sin demora nuestra demanda quedará concluida. 
TOMÁS RODRÍGUEZ RUBÍ Y EL DRAMA HISTÓRICO DE INTENCIÓN POLÍTICA

Vencimos, Condestable: los proyectos

de los que osaron levantar escalas

por mi influjo contrastar, en breve,

caerán ante mis pies: sin pesadumbre"

$\left(2^{a}\right.$ parte, $\left.3^{\circ}, 4^{a}, 93\right)$

Y cuando se entera por boca del Duque de que Carlos II ha elegido como esposa a quien ella no desea, no le queda más alternativa que reconocer su derrota:

Duque: "Don Carlos ha tenido a bien mandarme que ante su Corte revele, que de propia voluntad libre y espontáneamente al trono de San Fernando como esposa y reina asciende a Luisa de Borbón. de la muy alta progenie de la casa de Orleans.

Reina: ( $\quad$ (Oh!... ique su astucia me venza!...) (Escena última, 98)

Una derrota que será aún mayor al lograr el Duque ser nombrado Ministro Universal:

Duque: "Ninguno vuelva perjuro

la muerta hoguera a encender, porque hoy subo al poder, y en nombre del Rey le juro, que tiene el gobierno fuerza para velar por España: y sin que nada la tuerza, y sin influencia extraña, desde el uno al otro mar, desde el viejo al nuevo mundo, otra voz no ha de sonar que la de Carlos segundo." (Escena última, 99) 
3. Acogida de la obra por la crítica y el público:

Casi con plena certeza de haberse representado nuestro autor hubiera logrado un completo éxito. Al no poder hacerlo Rubí optó por reescribir el texto en 1852 bajo el título de Tres al saco, eliminado del mismo toda alusión a la Reina Madre.

\section{c. Alberoni, (1846)}

El orgullo y el amor propio del escritor malagueño eran más fuertes que los ataques de la censura dramática. Con Alberoni vuelve Rubí a desafiar a la autoridad. A tal atrevimiento hace mención Narciso Alonso Cortés, para quien el dramaturgo "escribe una comedia que a los pocos días de su estreno fue prohibida por la autoridad. Era una comedia en clave, en la que aparecían disimulados varios personajes del día, incluso el mismo autor, encubierto bajo el nombre de Zamora. ${ }^{\text {39 }}$

\section{Argumento de la obra:}

Dolorido nuestro autor por los abusos que cometía el poder prohibiendo sus obras, nos presenta aquí una Princesa de los Ursinos que es vivo reflejo de María Cristina. Ursinos y el Cardenal Alberoni se disputan el favor de Felipe V por obtener el nombramiento de Ministro Universal. Complica el autor la trama al utilizar el "teatro dentro del teatro" como directa venganza de quienes censuraban sus textos. A tal fin elabora como trama secundaria otra comedia en la que él mismo, bajo el nombre el famoso actor Antonio Zamora, será el protagonista.

Pero en esta ocasión volvió Rubí a caer en el mismo error, pues al hacer lectura pública del texto, alguien dio parte a las autoridades y estas lo prohibieron a los pocos días del estreno. Montó el autor en cólera y ante este nuevo atentado a la libertad de expresión y a sus intereses económicos, replicó en una dura carta al Ministro de la Gobernación con estas palabras:

"Exmo. Sr.

Por la autoridad del Jefe Superior Político de Madrid, D. Pedro Sabater, se suspendieron las representaciones de mi última comedia Alberoni, al día

39. Narciso Alonso Cortés. Ob. cit., p. 288.

Esta misma consideración es expuesta por David Thatcher Gies, quien nos informa que: "en Alberoni aparece un personaje singular, otra figura al estilo de María Cristina; la obra fue prohibida después de obtener una acogida ruidosa y entusiasta la noche del estreno." Cf. David Thatcher Gies. Ob. cit., p. 234,

En idéntico sentido se manifiesta Salvadora Agudo Pérez, quien nos precisa que: "en Alberoni Rubí se desvía hacia la censura político-moral." Cf. Salvadora Agudo Pérez. Art, cit., p. 61 
TOMÁS RODRÍGUEZ RUBÍ Y EL DRAMA HISTÓRICO DE INTENCIÓN POLÍTICA

siguiente a haberse estrenado en el Teatro del Príncipe con un éxito que prometía una serie de entradas numerosas. No habiendo podido tener esto lugar por disposición de aquel Jefe, y consistiendo la remuneración de mis obras en un tanto sobre las entradas que producen, el exponente no cuenta por otro patrimonio que el producto de sus composiciones dramáticas.

Por tanto acudo a V.E. suplicándole que así como al Empresario del Príncipe se le ha administrado justicia sobre este particular, tenga a bien mandar se me indemnice del directo perjuicio que ha sufrido mi propiedad en los términos que la ilustrada justificación de V.E.tenga por convenientes.

Dios guarde a V.E. muchos años. Madrid, 16 de mayo de 1847. Exmo. Sr. Ministro de la Gobernación." ${ }^{140}$

2. Descripción de los contenidos de claro alcance e intención política:

La Princesa de Ursinos, valida de Felipe V, ejerce el poder de modo despótico y arbitrario y aparta de su camino a todo quien se oponga a su ambición por ser nombrada Ministro Universal. En tal sentido prohibe los amores de Camila, su sobrina, con Antonio Zamora, el poeta:

Camila: "No hay reparo en cuanto a mi... pero olvidáis quien es ella.

Zamora: Princesa de los Ursinos es, y por más blasón dirige de esta nación hace tiempo los destinos. Que su voluntad es ley se también, nadie lo ignora, y que en nuestra España ahora es ella el gobierno, el rey." $\left(I, 1^{a}, 7\right)$

Toda una directa referencia a poder casi absoluto que ejercía María Cristina, la Reina Madre, en la corte isabelina.

Herido Zamora por tal prohibición busca en el Cardenal Alberoni consejo, y este le explica las claves del arte de la política:

Zamora: "Como no éramos profanos, y sin testigos ahora...

Alberoni: En política, Zamora, no hay amigos, no hay hermanos.

40. Tomás Rodríguez Rubí. A.H.N. Consejos, leg. 11318. 


\section{VÍCTOR CANTERO GARCÍA}

$Y$ aunque exacto por demás eso fuera allá en lo interno, de la boca de un gobierno no debe salir jamás."

$\left(I, 5^{a}, 16\right)$

Una explicación en la que el autor concentra la tesis de su obra; a saber: en política no hay que fiarse de nadie, sino ser más astuto y hábil que tu contrincante para alzarte con el poder. En esa lucha se enzarzan Ursinos y Alberoni, siendo éste quien acabe derrotando a la ambiciosa Princesa:
Alberoni: "Que apuren la amarga copa cabezas como la mía tienen que hacer algún día la revolución de Europa. Por de pronto este resorte producirá....lo estoy viendo.... no va a ser malo el estruendo que voy a armar en la corte. Dicen que han dado en creer que Alberoni en este instante es hombre poco importante de quien nada hay que temer.... Pues yo sabré en esta empresa derribar pese i pese al infierno! con la comedia al gobierno: con la boda a la Princesa." $\left(I, 10^{a}, 24\right)$

Ella encaja muy mal su la amarga derrota, pues se siente engañada por la astucia de Alberoni:

Camila: ¿Qué ha ocurrido? ¿qué tenéis querida tía?

Princesa: ¿Qué ha de ser, sobrina mía? ¿Qué ha de ser?...que me han vendido. Que aquel en quien yo he fiado, que aquel a quien yo escuché con la mejor buena fe.... es el que más me engañado." (II, $\left.5^{a} 66\right)$ 
Un Alberoni que al final se alza con la victoria y obtiene el codiciado nombramiento:

Zamora: "Alberoni, vamos claros, ¿qué es esto que pasa ahora?

Alberoni: Que hoy es mi fortuna tal que sin mérito cumplido nombrarme el Rey se ha servido su Ministro Universal $\left(I V, 8^{a}, 71\right)$

Aprovecha Rubí la ocasión para rematar la pieza con una proclama patriótica con la que enciende el ánimo de los espectadores contra cualquier injerencia extranjera en nuestros asuntos de Estado:

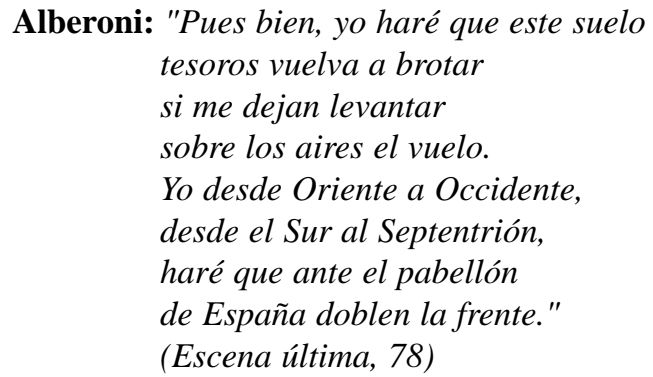

3. Acogida de la obra por la crítica y el público:

Tal como nos indica Ana $\mathrm{M}^{\mathrm{a}}$ de Burgos "con Alberoni, Rubí volvió a las andadas, y el escándalo fue tan grande, que se prohibió a raíz del estreno, muy brillante por cierto. ${ }^{41}$ Esta opinión es ratificada por el cronista de El Heraldo, quien apostilla que: "fue ruidosa y entusiásticamente recibido en su estreno. Fue motivo de gran polémica en los periódicos del día siguiente y la autoridad lo prohibió. ${ }^{42}$

Hasta aquí llegan nuestras consideraciones y apuntes, con los que pretendemos acercar al lector la obra de un dramaturgo y político que supo dejar un sello de distinción y buen hacer en medio de las agitaciones sociopolíticas de la segunda mitad de XIX. 
